\title{
Change of Fatigue and Mechanical Fracture Properties of a Cement Composite due to Partial Replacement of Aggregate by Red Ceramic Waste
}

\author{
Stanislav Seitl ${ }^{1,2}$, Petr Miarka², Hana Šimonová2, Petr Frantík², Zbyněk Keršner ${ }^{2}$, Jacek Domski ${ }^{3}$, \\ Jacek Katzer ${ }^{3 *}$ \\ 1 Institute of Physics of Materials, \\ Academy of Science of the Czech Republic \\ 60200 Brno, Žižkova 22, Czech Republic \\ 2 Faculty of Civil Engineering, , \\ Brno University of Technology, \\ 60200 Brno, Veveří 331/95, Czech Republic \\ ${ }^{3}$ Faculty of Civil Engineering, \\ Environmental and Geodetic Sciences, \\ Koszalin University of Technology, \\ 75-453 Koszalin, ul. Śniadeckich 2, Poland \\ * Corresponding author, e-mail: jacek.katzer@tu.koszalin.pl
}

Received: 23 April 2018, Accepted: 05 December 2018, Published online: 08 January 2019

\begin{abstract}
Fine-grained cement-based composites used in civil engineering and construction industry are usually made of cement-based matrix and natural aggregate (such as sand, gravel, crushed stone, etc.). Red ceramic waste aggregate is considered as a perspective replacement of a part of natural aggregate in modern environmentally oriented building materials. Fine-grained cement composite with natural aggregate partially replaced by ceramic waste aggregate usually show different mechanical fracture characteristics from ordinary fine-grained concrete. The specimens were tested at six different ages. This was the reason for conducting the research programme. Altogether, 6 fine-grained cement mixtures with various proportions of natural and red ceramic waste aggregate were prepared. The aim of this paper is to present and compare mechanical fracture properties obtained from static and fatigue tests. Bulk density, flexural and compressive cube strength, fracture toughness and fatigue properties (S-N - Wöhler curve) were of special interest. All of these tests are important for a practical application of concrete with ceramic aggregate for structures. All the results were statistically analysed and they showed that the fatigue and mechanical fracture properties were improved or at least kept up with the increasing levels of red ceramic waste aggregate. Environmental impact of application in construction industry of composites in question is discussed.
\end{abstract}

\section{Keywords}

ceramic waste, aggregate, strength characteristics, fatigue properties, S-N curve

\section{Introduction}

Concrete is considered the second (after water) most utilized material in the world. It was estimated that the world uses twenty-five billion tonnes of concrete every year $[1,2]$. Concrete is the mixture of cement, aggregate and water in which the aggregate constitutes $65-80 \%$ of total volume. The increase in industrialization and urbanization rates due to economic and population growth has turned construction industry into one that consumes the most of natural resources and generates solid waste that negatively

impacts the environment [3]. It is justified to affirm that the use of recycled aggregate is a way to reduce the impact concrete production may cause to the environment [4, 5]. Incorporating the maximum possible amount of recycled material in concrete would contribute to the reduction of greenhouse gases emission as well as to minimize the amount of energy spent in concrete production. Kumar Sharma et al. [6] mentioned that for the concrete containing polished granite waste, concrete with up to $20 \%$ of 
natural coarse aggregate substituted by granite waste could be recommended for all applications, while concrete with $20 \%$ to $40 \%$ of natural coarse aggregate substituted by granite waste could be recommended for non-structural applications, pavements etc.

Ceramic is one of the oldest and most commonly harnessed material in the history of mankind. It has been used for multiple and varied applications such as pottery, chinaware and sanitary ware $[7,8]$. Ceramic is also harnessed in construction industry as building material (e.g. for ceramic floor and wall tiles, for various building bricks and hollow blocks). The global volume of construction and demolition waste is dominated by red ceramic waste [9, 10, 11]. It was proven that the most promising recycling process of red ceramic waste is utilizing it for concrete production as coarse aggregate [12]. Worldwide, there is a significant and growing research effort to efficiently use ceramic waste in construction industry [13]. Replacing natural coarse aggregate by waste ceramic aggregate is one of a rapidly developing recycling technology. Waste ceramic aggregate significantly influences the homogeneity of mechanical characteristics of cast concrete. Populations of test results (of any tested property) of any concrete based on waste ceramic are characterized by significantly higher standard deviation [9, 14]. This phenomenon significantly limits possible applications of waste ceramic aggregate concrete. Currently, waste ceramic aggregate concretes are only used for construction elements characterized by less demanding mechanical characteristics. In this context, this research programme aims to contribute to the complex analysis of the effect of red ceramic waste aggregate (RCWA) on fatigue and mechanical fracture properties of fine-grained cement composite. Such properties as: bulk density, flexural strength, compressive strength, fracture toughness and Wöhler curve properties were tested during the research programme. The specimens were tested at six different ages $(3,7,14,28,90$, and 780). The impact of partial and full replacement of natural aggregate by RCWA on fatigue characteristics, mechanical fracture properties and environmental is discussed.

\section{Materials and specimen preparation}

Assessment of mechanical characteristics of fine-grained cement composites with RCWA was conducted utilizing mortar test specimens made in standard steel moulds $(40 \mathrm{~mm}$ $\times 40 \mathrm{~mm} \times 160 \mathrm{~mm}$ ). CEM I $42.5 \mathrm{R}$ was used as a binder. A reference composite was prepared using mix proportions of a standardized mortar for cement tests $(w / c=0.5)$. The volume composition of the mortar is presented in Fig. 1.

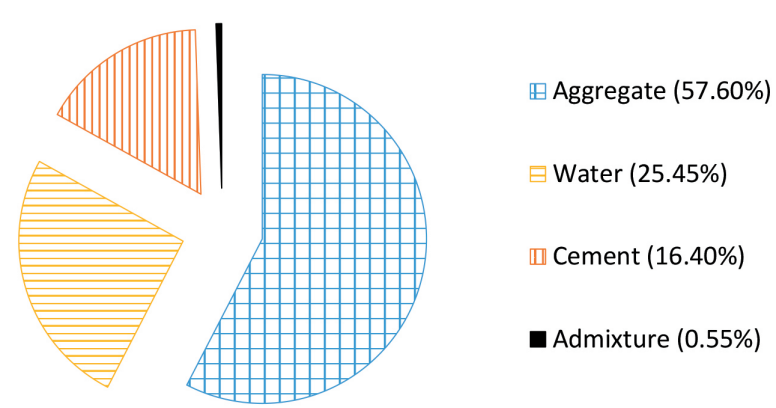

Fig. 1 Volume composition of the cement mortar

Both used aggregates ( $d \leq 2 \mathrm{~mm})$ : natural sand and RWCA were mirroring grading characteristics of the standardized sand according to EN 191-1 [15]. The natural sand was replaced by volume due to lower bulk density of RWCA. The created mixtures are marked from 1 to 6 , where mixture 1 contains only natural aggregate and mixtures from 2 to 6 contain increasing volumes of RCWA (6.35\%, $12.70 \%, 19.05 \%, 25.40 \%, 31.75 \%$ respectively). All studied mixtures were prepared using a small laboratory mixer for mortars. The amount of cement, water and admixture was equal to $450 \mathrm{~g}, 225 \mathrm{~g}$ and $5 \mathrm{~g}$ respectively for one batch (allowing casting of three specimens). These amounts were constant for all cast composites. No adjustment of fresh batches on the level of uniform value of plasticity or workability was carried out. Due to the fact that porous and dry red ceramic sucks the water whenever possible, it is impossible to assess the real composition of the mix and subsequently the value of $w / c$ ratio. During the current research programme admixture was used to maintain the similar workability of all the mixes but the amount of water absorbed by the RCWA is unknown. One may argue that the fresh mortars had to have different $w / c$ influencing the strength values of individual batches. In authors opinion it is a combined effect of a difference in value of $w / c$ and internal curing which is happening afterwards. Basically, the more water is sucked by RCWA the lower value of $w / c$, hence the larger strength of hardened composite, and larger scale of internal curing also influencing strength characteristics. The initial amount of natural sand was equal to $1350 \mathrm{~g}$. The procedure for mixture preparation and compaction of a standardized cement mortar was used for preparation of all mixes. The volume of each mixture was equal to $30 \mathrm{dm}^{3}$. Immediately after mixing, fresh mixture was poured into steel moulds. The prism specimens with nominal dimensions of $40 \mathrm{~mm} \times 40$ $\mathrm{mm} \times 160 \mathrm{~mm}$ were prepared for testing. The specimens were demoulded at the age of 24 hours and placed in a water tank with constant water temperature of $20 \pm 1^{\circ} \mathrm{C}$. 
Table 1 Composition of studied mixtures

\begin{tabular}{lcccccc}
\hline $\begin{array}{l}\text { Com- } \\
\text { posite }\end{array}$ & Cement & Water & Sand & RWCA & $\begin{array}{c}\text { Super- } \\
\text { plasticizer }\end{array}$ & $\begin{array}{c}\text { Bulk } \\
\text { density }\end{array}$ \\
\hline & $(\mathrm{g})$ & $(\mathrm{g})$ & $(\mathrm{g})$ & $(\mathrm{g})$ & $(\mathrm{g})$ & $\left(\mathrm{kg} / \mathrm{m}^{3}\right)$ \\
1 & 450 & 225 & 1350 & 0 & 5 & 2270 \\
2 & 450 & 225 & 1215 & 101 & 5 & 2235 \\
3 & 450 & 225 & 1080 & 202 & 5 & 2185 \\
4 & 450 & 225 & 945 & 304 & 5 & 2135 \\
5 & 450 & 225 & 788 & 394 & 5 & 2125 \\
6 & 450 & 225 & 657 & 493 & 5 & 2110 \\
\hline
\end{tabular}

They were cured in these conditions until the tests were performed. The specimens were firstly used for the flexural test. The remaining halves of the specimens after flexural strength tests were subsequently used for compressive strength tests. Easy compaction of fresh mixture is an important property enabling achieving the maximum possible strength of any cement composite. It was observed that in case of mixtures with RCWA, workability is deteriorating with the increasing amount of added RCWA. This phenomenon was described by Rashid et al. [16] The decrease in workability is partially caused by RCWA being capable of absorbing significant amount of water $[8,17]$ due to porosity. Other reason for the reduction of the workability is shape of the RCWA [17]. The amount of water required for maintaining the fluidity of fine-grained cement composite only with RCWA is very high. Therefore, the maximum volume of natural aggregate replacement by RCWA was limited to $493 \mathrm{~g} / 1350 \mathrm{~g}$ (see Table 1). To ensure desired workability, all mixtures were modified by the addition of a commercially available superplasticizer based on polymers and characterized by density of $1.07 \mathrm{~kg} / \mathrm{dm}^{3}$ and $\mathrm{pH}$ equal to $4.4 \pm 1.0$.

Designers of civil engineering structures use or refer to the composite 1 design curve as the lower bound for their analyses. It is well known [18] that cement industry produces a significant amount of $\mathrm{CO}_{2}$. Ultimately, the produced $\mathrm{CO}_{2}$ affects the environment. Therefore, environmental impact of fine-grained cement composite is evaluated using the volume of raw materials: cement, sand and RCWA aggregate etc. In studied mixtures of fine-grained cement composites with RCWA, volume of raw materials is calculated by using data from Table 1 and normalized with the control specimen.

The volume of raw material is reduced almost linearly with the increase in RCWA. About 20 and $25 \%$ reduction is observed with 30 and $36 \%$ replacement of natural aggregate by RCWA, respectively (see Fig. 2).

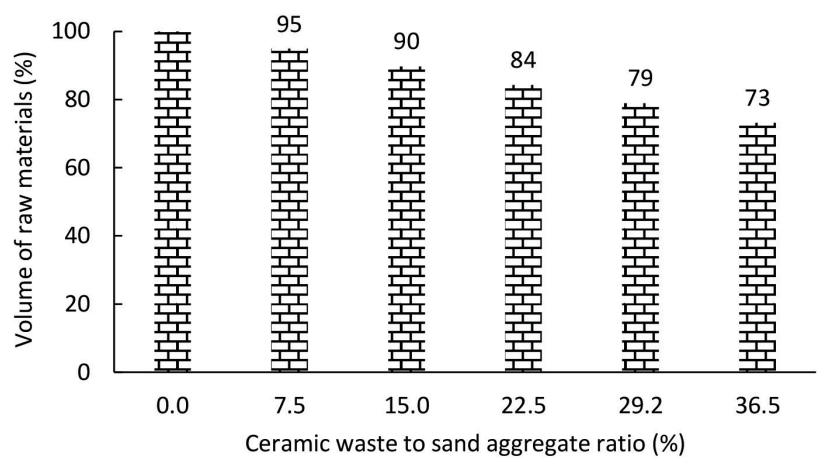

Fig. 2 Environmental impact assessment for all tested fine-grained composites with RCWA

\section{Methods of testing}

The flexural and compressive strength tests were conducted in compliance with EN 196-1. The flexural strength tests were conducted using a three point bending test (3PBT) on prismatic specimens $(40 \mathrm{~mm} \times 40 \mathrm{~mm} \times 160 \mathrm{~mm})$. The compressive strength test was conducted on halves of prismatic specimens remaining after performing flexural strength tests. For calculation of fracture toughness values, the data from 3PBT was evaluated. The 3PBT was successfully used for such evaluations by numerous researchers [19, 20 21]. Notched (by a diamond blade saw) prism specimens with nominal dimensions $40 \mathrm{~mm} \times 40 \mathrm{~mm} \times$ $160 \mathrm{~mm}$ are prepared for the test. The notch must keep a crack - length relation equal to 0.1 . The span length for this test is equal to $120 \mathrm{~mm}$. During the test, the maximum values of force were recorded. Then linear elastic fracture mechanics (LEFM) equation was used [22]:

$K=\sigma \sqrt{\pi a} f(a / W)$,

where: $a$ - crack length, $W$ - width of a specimen, $f-$ dimensionless functions for ratio span/width $=3$ is Eq.(2), $K$ - stress intensity factor, $\sigma$ - corresponding load Eq.(3)

$$
\begin{aligned}
& f(a / W)=0.9926+0.4862(a / W)-12.479(a / W)^{2} \\
& +73.153(a / W)^{3}-124.29(a / W)^{4},
\end{aligned}
$$

used by Wu [23], Karihaloo [19], Tada [22], etc.

$\sigma=3 S P /\left(2 B W^{2}\right)$,

where: $S$ - span, $P$ - force, $B$ - thickness, $W$ - width of a specimen.

When the force reaches maximum value $P_{\text {max }}$ the value of the stress intensity factor $K_{I}$ is called fracture toughness $K_{I C}$. Fatigue properties were also gained from 3PBT. The depth of the notches was $4 \mathrm{~mm}$ for fatigue tests. The fatigue tests were carried out at the Laboratory of 
High-cycle Fatigue Group at the Institute of Physics of Materials at Brno University of Technology. The controlled values for temperature and relative humidity were equal to $22 \pm 2{ }^{\circ} \mathrm{C}$ and $50 \% \pm 2 \%$ respectively. The fatigue experiments were carried out using a computer-controlled servo-hydraulic testing machine under load control. The stress ratio $R$ (defined as quotient of minimum $P_{\min }$ and maximum $P_{\max }$ load of a sinusoidal wave in each cycle) was equal to 0.1 . The load frequency used for all tests was equal to $10 \mathrm{~Hz}$. Fatigue endurance limit was determined on the basis of an $S-N$ curve. The limit of $2 \times 10^{6}$ cycles to fracture was used to consider the applied stress amplitude as safe for loading during the whole component lifetime. The testing procedure based on applying cyclic loading with defined stress amplitude to determine the number of cycles to the fracture was described by multiple researchers $[24,25,26]$.

\section{Results and discussion}

The bulk density of all hardened composites after 28 days of curing is presented in Fig. 3 [27, 28]. One of the advantage of using the RWCA is that the value of bulk density slightly decreases with an increased amount of RWCA used as a replacement of natural aggregate.

Mixtures with natural aggregate are characterized by higher bulk density due to weight of aggregate in comparison with RWCA. Bulk density of reference mixture is equal to $2270 \mathrm{~kg} / \mathrm{m}^{3}$. The bulk density of the composite with the maximum amount of RWCA is reduced by $7 \%$ in comparison to a composite with no RWCA. Similar trends have been described by Medina et al. [17]. The obtained results from the flexural test and adequate coefficient of variation $(\mathrm{CoV})$ are presented in Table 2.

The mean values and coefficients of variation are introduced for specimens at the age of 3, 7, 14, 28, 90, and 180 days. It is observed that flexural strength increase with age. For specimens of age from 3 to 28 days, there is observed expected increase of about $10-15 \%$ in the flexural strength (for mixture 6 it is only $6 \%$ ). From 28 to 180 days of specimens' age, increase in the flexural strength of 24-30\% was observed for all mixtures. Mixtures with RCWA yielded higher flexural strength in comparison with the control fine-grained cement composite (mixture 1) for the same specimens' ages. It is worth noticing that with the increasing substitution rate of natural aggregate with RWCA the flexural and compressive strength increase with increasing age of the specimens. The obtained results from the compressive strength test are mentioned in Table 3.

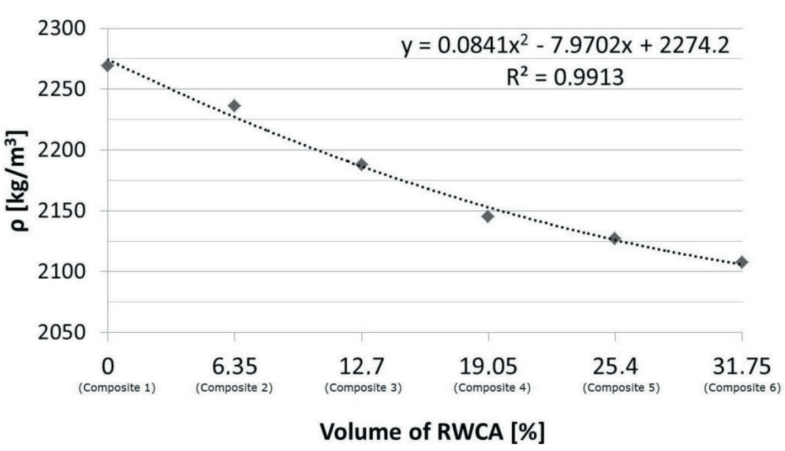

Fig. 3 Influence of RWCA addition on bulk density of hardened composite

Table 2 Mean values of flexural strength in $\mathrm{MPa}(\mathrm{CoV}$ in \%)

\begin{tabular}{lcccccc}
\hline $\begin{array}{l}\text { Com- } \\
\text { posite }\end{array}$ & 3 days & 7 days & 14 days & 28 days & 90 days & 180 days \\
\hline 1 & 4.9 & 5.5 & 6.1 & 5.7 & 7.3 & 7.5 \\
& $(6.2)$ & $(3.4)$ & $(1.5)$ & $(2.8)$ & $(3.4)$ & $(2.4)$ \\
2 & 5.7 & 6.1 & 6.3 & 6.3 & 7.7 & 8.5 \\
& $(2.9)$ & $(5.4)$ & $(1.7)$ & $(5.9)$ & $(6.2)$ & $(5.6)$ \\
3 & 6.0 & 6.6 & 6.7 & 6.9 & 8.4 & 9.2 \\
& $(2.5)$ & $(6.1)$ & $(4.2)$ & $(4.6)$ & $(3.2)$ & $(2.3)$ \\
4 & 6.0 & 6.8 & 7.4 & 7.6 & 7.9 & 10.3 \\
& $(4.2)$ & $(1.4)$ & $(2.6)$ & $(13.8)$ & $(1.4)$ & $(3.9)$ \\
5 & 6.6 & 7.8 & 8.1 & 7.3 & 8.1 & 10.3 \\
& $(4.0)$ & $(1.5)$ & $(2.8)$ & $(6.8)$ & $(8.3)$ & $(4.9)$ \\
6 & 7.3 & 7.8 & 8.7 & 7.8 & 8.2 & 10.8 \\
& $(2.8)$ & $(3.8)$ & $(3.7)$ & $(0.7)$ & $(11.5)$ & $(7.0)$ \\
\hline
\end{tabular}

Table 3 Mean values of the compressive strength in $\mathrm{MPa}(\mathrm{CoV}$ in \%)

\begin{tabular}{lcccccc}
\hline $\begin{array}{l}\text { Com- } \\
\text { posite }\end{array}$ & 3 days & 7 days & 14 days & 28 days & 90 days & 180 days \\
\hline 1 & 32.0 & 34.2 & 39.6 & 46.1 & 61.4 & 62.0 \\
& $(1.3)$ & $(1.9)$ & $(5.3)$ & $(1.9)$ & $(1.9)$ & $(3.1)$ \\
2 & 34.8 & 39.3 & 44.2 & 51.1 & 66.9 & 61.5 \\
& $(0.9)$ & $(0.7)$ & $(1.7)$ & $(2.2)$ & $(2.5)$ & $(4.2)$ \\
3 & 37.2 & 43.4 & 47.1 & 58.4 & 77.0 & 71.3 \\
& $(1.5)$ & $(0.4)$ & $(1.7)$ & $(1.2)$ & $(1.8)$ & $(2.7)$ \\
4 & 39.3 & 45.4 & 51.9 & 57.2 & 75.0 & 80.6 \\
& $(1.9)$ & $(2.3)$ & $(2.2)$ & $(9.0)$ & $(2.6)$ & $(0.6)$ \\
5 & 42.9 & 50.6 & 53.1 & 61.9 & 80.4 & 78.9 \\
& $(0.8)$ & $(2.3)$ & $(6.2)$ & $(3.2)$ & $(2.5)$ & $(4.6)$ \\
6 & 45.3 & 50.3 & 57.7 & 63.6 & 80.5 & 80.1 \\
& $(2.4)$ & $(1.8)$ & $(2.2)$ & $(4.1)$ & $(6.2)$ & $(5.3)$ \\
\hline
\end{tabular}

The mean values and coefficients of variation are introduced for specimens at the age of 3, 7, 14, 28, 90, 180, and 780 days. It is observed that the compressive strength increases with the increasing specimens' age. For specimens 
3 to 28 days, about $28-37 \%$ increase in the compressive strength is observed for all mixtures, similar to the results described by Rashid et al. [16]. For specimens 28 to 780 days of age, increase in the compressive strength is between $17-27 \%$, but major increase was happening at the age of around 90 days. At all testing periods, RCWA mixtures are yielded higher compressive strength than the control finegrained cement composite mixture 1 .

The improvement in mechanical properties (flexural and compressive strength) with addition of RWCA is achieved due to the rough shape of ceramic waste aggregate and hence providing more surface area [29]. The obtained results of fracture toughness for fine-grained cement composite with RCWA at the age of 28 days according to equation 1 are presented in Table 4 . The increase in fracture toughness is $25 \%$ (for mixture 6 ). It is worth noticing that fracture toughness for mixture 2 and 6 is characterized by the highest value of the $\mathrm{CoV}$ (around $10 \%$ ).

The fatigue experiments usually last for a long time, which is problematic from the point of view of the ageing of the specimen material. Because of this, the data obtained from the fatigue tests were standardized to a specimens' age of 28 days. Selected approximation curves (Table 5) obtained from compressive strength values over time were used for this purpose. The used procedure was described in details by Šimonová et al. [26]. The measured values of compressive strength were divided with mean value at the age of 28 days (see respective column in Table 3) and this way the relative values for all investigated ages of specimens were obtained. These values were then approximated by the selected function:

$y=a\left(1-\frac{1}{b^{(c+d x)}}\right)$,

where: $x$ - time in days; $y$ - the dimensionless relative value of the compressive strength; $a$ - coefficient representing an asymptote to the approximation curve expressed as the ratio between the theoretical value of the compressive strength at the age $t=\infty$ and the determined mean value of compressive strength at the age of 28 days; $b, c, d$-coefficients expressing the extent of the time-dependent change of compressive strength in the interval $t=(0, \infty)$, which is generally dependent on the parameters of the used mixture and also on the conditions of the environment in which the specimens are stored.

Approximation was performed with nonlinear least-square method provided by genetic algorithms implemented in the open source Java GA package as proposed by Frantík [30].
Table 4 Fracture toughness, KIC

\begin{tabular}{lcc}
\hline Composite & Mean values $K_{\mathrm{IC}}\left(\mathrm{MPa} \cdot \mathrm{m}^{1 / 2}\right)$ & $\mathrm{CoV}(\%)$ \\
\hline 1 & 0.543 & 2.51 \\
2 & 0.539 & 9.04 \\
3 & 0.580 & 4.63 \\
4 & 0.649 & 2.83 \\
5 & 0.666 & 2.99 \\
6 & 0.676 & 10.70 \\
\hline
\end{tabular}

Table 5 Coefficients of analytical expressions for approximation curves for compressive strength

\begin{tabular}{lcccc}
\hline $\begin{array}{l}\text { Com- } \\
\text { posite }\end{array}$ & $\mathrm{a}$ & $\mathrm{b}$ & $\mathrm{c}$ & $\mathrm{d}$ \\
\hline 1 & 1.3637 & 0.3881 & -0.6441 & -0.0287 \\
2 & 1.2559 & 1.4191 & 1.9086 & 0.1049 \\
3 & 1.2532 & 0.0973 & -0.2537 & -0.0161 \\
4 & 1.3717 & 0.1292 & -0.3168 & -0.0131 \\
5 & 1.2962 & 0.1264 & -0.3383 & -0.0148 \\
6 & 1.2635 & 0.7766 & -2.9255 & -0.1331 \\
\hline
\end{tabular}

The coefficients of approximation curves of individual series are presented in Table 5. The formula for fitting the experimentally obtained data from fatigue test used in this paper is based on empirically derived $S-N$ diagrams known as Wöhler curves:

$S=a \times N^{b}$

where: $a, b$ - the material constants characterising the $S-N$ curve.

In an ideal, theoretical case, all specimens at a certain stress level would fail after the same number of cycles. However, the fatigue behaviour of heterogeneous material like fine-grained cement composite is far from being ideal, so the results are usually highly scattered. Accordingly, it is necessary to determine not only the analytical expression of the relevant $S-N$ curve but also a measure of the scatter, such as the coefficient of determination $R^{2}$. According to the equation (5), the power functions and the coefficient of determination for individual series are introduced in following figures (Fig. 4-9). The crosses represent measured data and diamonds represent data standardized at the age of 28 days.

To have a clear view how replacement of natural aggregate by RCWA influences fatigue life, the endurances of all specimens standardized at the age of 28 days are presented in Fig. 10. It can be seen that the fatigue endurances for fine-grained composites with RCWA are consistently higher than reference composite 1 notably in the long life 


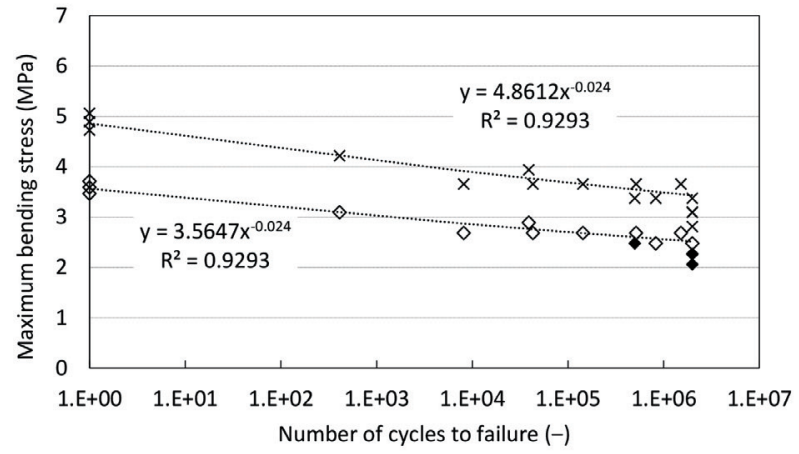

Fig. 4 Fatigue behaviour - mixture 1 (measured and corrected to 28 days age data)

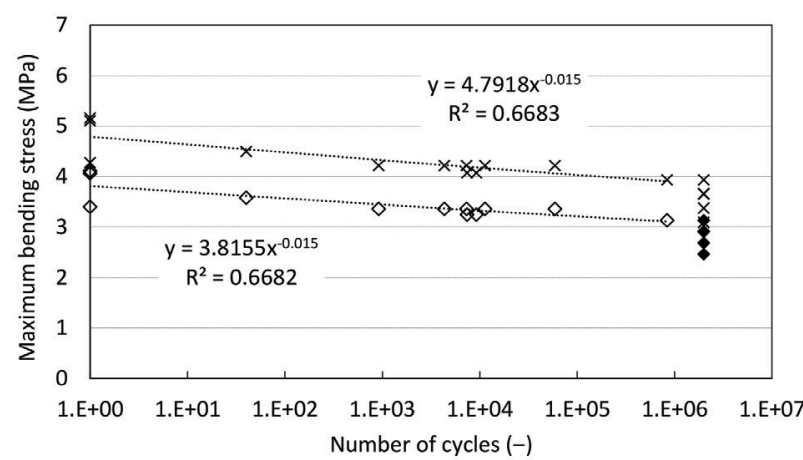

Fig. 5 Fatigue behaviour - mixture 2 (measured and corrected to 28 days age data)

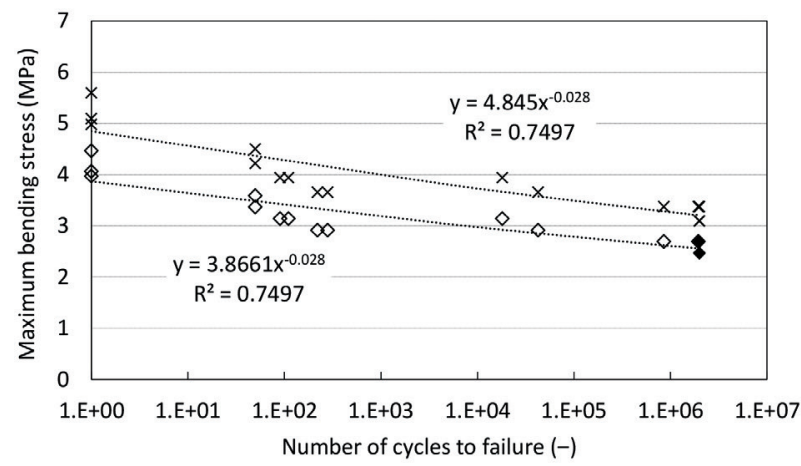

Fig. 6 Fatigue behaviour - mixture 3 (measured and corrected to 28 days age data)

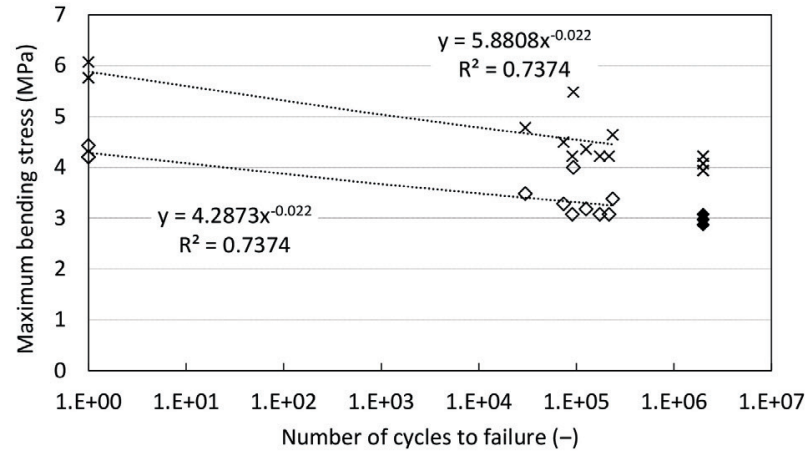

Fig. 7 Fatigue behaviour - mixture 4 (measured and corrected to 28 days age data)

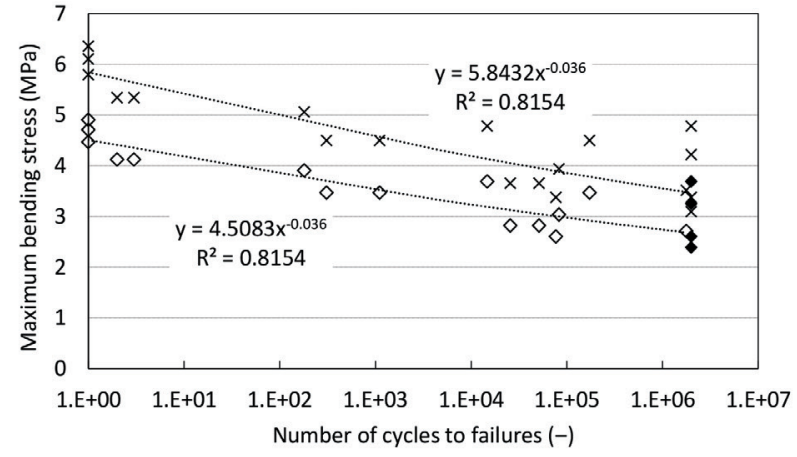

Fig. 8 Fatigue behaviour - mixture 5 (measured and corrected to 28 days age data)

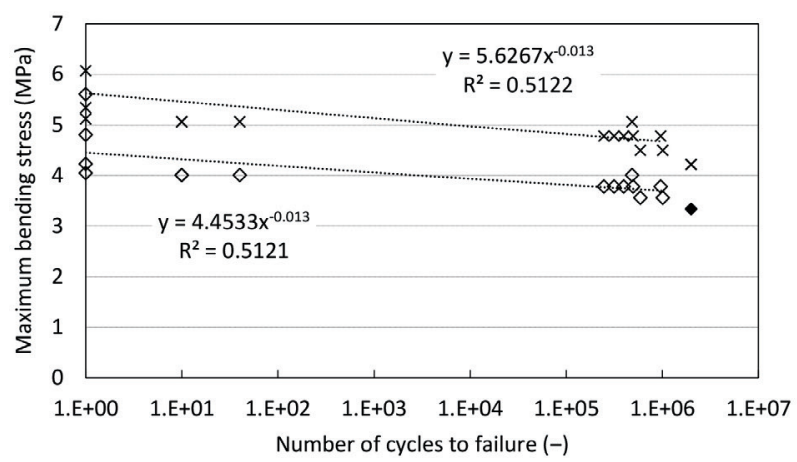

Fig. 9 Fatigue behaviour - mixture 6 (measured and corrected to 28 days age data)

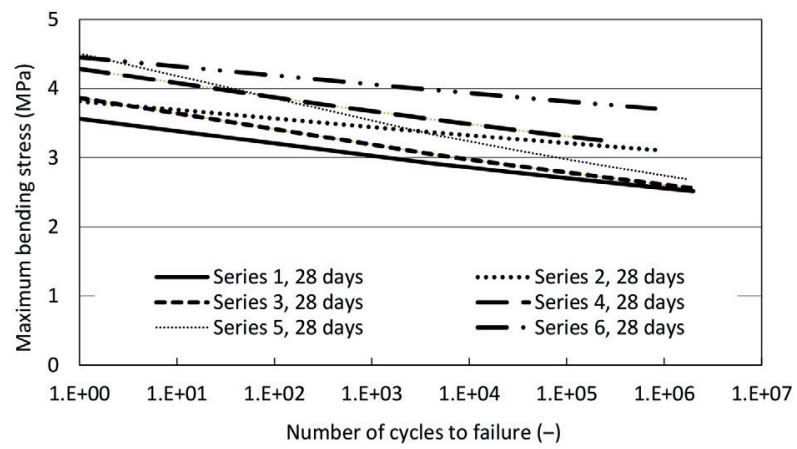

Fig. 10 Mean values of the fatigue performance standardized at the specimens' age of 28 days

regime $\left(2 \times 10^{6}\right.$ cycles $)$. Basically, with increasing amount of RCWA substitution of natural aggregate the fatigue endurance increases. This trend is as expected from the mechanical analysis because fine-grained composites with RCWA show higher flexural strength.

\section{Conclusions}

The results of this study indicate that the use of RCWA as a replacement for natural aggregate in fine-grained cement composite is certainly feasible and the following conclusions can be drawn from the research programme described in the paper: 
1. Mixtures with RCWA allow to achieve the flexural strength, compressive strength and fracture toughness of a cement composite higher than in case of ordinary natural aggregate.

2. With increasing substitution rate of natural aggregate with RCWA the composites bulk density decrease, however, its workability reduces as well.

3. With $36 \%$ replacement of natural sand with RCWA (composite 6) the best fatigue and mechanical fracture properties were achieved.

4. A further study of the influence of the RCWA should be done in order to reveal toughening mechanisms of quasi-brittle materials of this kind.

\section{Acknowledgement}

Financial support from the Czech Science Foundation, project 16-18702S (AMIRI), is gratefully acknowledged. This paper has been worked out under the "National Sustainability Programme I" project "AdMaS UP Advanced Materials, Structures and Technologies" (No. LO1408) supported by the Ministry of Education, Youth and Sports of the Czech Republic and Brno University of Technology. Results presented in this paper are direct outcome of the specific collaboration agreement between the Koszalin University of Technology, Department of Civil and Environmental Engineering, and the Brno University of Technology, Faculty of Civil Engineering.

\section{References}

[1] Task Group 3.1 "Environmental Issues in Prefabrication", International Federation for Structural Concrete (fib), Lausanne, Switzerland, Rep. 21, 2003.

[2] Task Group 3.4 "Environmental Effects of Concrete", International Federation for Structural Concrete (fib), Lausanne, Switzerland, Rep. 23, 2003.

[3] Behera, M., Bhattacharyya, S. K., Minocha, A. K., Deoliya, R., Maiti, S. "Recycled aggregate from C\&D waste \& its use in concrete - a breakthrough towards sustainability in construction sector: a review", Construction and Building Materials, 68, pp. 501-516, 2014.

https://doi.org/10.1016/j.conbuildmat.2014.07.003

[4] Limbachiya, M., Meddah, M. S., Ouchagour, Y. "Use of recycled concrete aggregate in fly-ash concrete", Construction and Building Materials, 27(1), pp. 439-449, 2012.

https://doi.org/10.1016/j.conbuildmat.2011.07.023

[5] Arel, H. S. "Recyclability of waste marble in concrete production", Journal of Cleaner Production, 131, pp. 179-188, 2016. https://doi.org/10.1016/j.jclepro.2016.05.052
[6] Sharma, N. K., Kumar, P., Kumar, S., Thomas, B. S., Gupta, R. C. "Properties of concrete containing polished granite waste as partial substitution of coarse aggregate", Construction and Building Materials, 151, pp. 158-163, 2017.

https://doi.org/10.1016/j.conbuildmat.2017.06.081

[7] Anderson, D. J., Smith, S. T., Au, F. T. K. "Mechanical properties of concrete utilizing waste ceramic as coarse aggregate", Construction and Building Materials, 117, pp. 20-28, 2016. https://doi.org/10.1016/j.conbuildmat.2016.04.153

[8] de Brito, J., Pereira, A. S., Correira, J. R. "Mechanical behavior of non-structural concrete made with recycled ceramic aggregates", Cement and Concrete Composites, 27(4), pp. 429-433, 2005. https://doi.org/10.1016/j.cemconcomp.2004.07.005

[9] Cichocki, K., Domski, J., Katzer, J., Ruchwa, M. "Impact resistant concrete elements with nonconventional reinforcement", Rocznik Ochrona Srodowiska, 16(2), pp. 1-92, 2014. Available at http://www.ros.edu.pl/images/roczniki/2014/pp_2014_02_01.pdf [Accessed: 05.12.2018]

[10] Correia, J. R., de Brito, J., Pereira, A. S. "Effects on concrete durability of using recycled ceramic aggregates", Materials and Structures, 39(2), pp. 169-177, 2006.

https://doi.org/10.1617/s11527-005-9014-7

[11] Lapko, A., Grygo, R. "Effectiveness of the use of recycling aggregate concrete for sustainable building structure", Rocznik Ochrona Srodowiska, 16(1),pp. 627-638, 2014.Available at http://www.ros.edu. pl/images/roczniki/2014/pp_2014_01_39.pdf [Accessed: 05.12.2018]

[12] Andreola, F., Barbieri, L., Lancellotti, I., Leonelli, C., Manfredini, T. "Recycling of industrial waste in ceramic manufacturing: State of art and glass case studies", Ceramics International, 42(12), pp. 13333-13338, 2016.

https://doi.org/10.1016/j.ceramint.2016.05.205

[13] Hendriks, Ch. F., Janssen, G. M. T. "Use of recycled materials in construction", Materials and Structures, 36(9), pp. 604-608, 2003. https://doi.org/10.1007/BF02483280

[14] Senthamarai, R. M., Manoharan, P. D. "Concrete with ceramic waste aggregate", Cement and Concrete Composites, 27(9-10), pp. 910-913, 2005.

https://doi.org/10.1016/j.cemconcomp.2005.04.003

[15] European Standards "Methods of testing cement. Determination of strength, BS EN 196-1", BSI Standards, London, United Kingdom, 2005.

[16] Rashid, K., Razzaq, A., Ahmad, M., Rashid, T., Tariq, S. "Experimental and analytical selection of sustainable recycled concrete with ceramic waste aggregate", Construction and Building Materials, 154, pp. 829-840. 2017. https://doi.org/10.1016/j.conbuildmat.2017.07.219

[17] Medina, C., Frías, M., de Rojas, M. I. S. "Microstructure and properties of recycled concretes using ceramic sanitary ware industry waste as coarse aggregate", Construction and Building Materials, 31, pp. 112-118, 2012. https://doi.org/10.1016/j.conbuildmat.2011.12.075

[18] Matar, W., Elshurafa, A. M. "Striking a balance between profit and carbon dioxide emissions in the Saudi cement industry", International Journal of Greenhouse Gas Control, 61, pp. 111-123, 2017. https://doi.org/10.1016/j.ijggc.2017.03.031 
[19] Karihaloo, B. L. "Fracture Mechanics and Structural Concrete", 1st ed., Longman Scientific \& Technical, Harlow, U.K., 1995.

[20] Pazdera, L., Topolář, L., Šimonová, H., Fojtu, P., Smutný, J., Havlíková, I., Keršner, Z., Rodriguezová, V. "Determine parameters for double-K model at three-point bending by application of acoustic emission method", Applied Mechanics and Materials, 486, pp. 151-156, 2014.

https://doi.org/10.4028/www.scientific.net/amm.486.151

[21] Veselý, V., Konečný, P., Lehner, P. "Influence of crack propagation on electrical resistivity and ultrasonic characteristics of normal concrete assessed by sequential TPB fracture test", Theoretical and Applied Fracture Mechanics, 80(A), pp. 2-13, 2015. https://doi.org/10.1016/j.tafmec.2015.09.005

[22] Tada, H., Paris, P. C., Irwin, G. R. "The Stress Analysis of Cracks Handbook", 3rd ed., The American Society of Mechanical Engineers, New York, U.S.A., 2000. https://doi.org/10.1115/1.801535

[23] Wu, S.-X. "Crack length calculation formula for three point bend specimens", International Journal of Fracture, 24(1), pp. R33R38, 1984.

https://doi.org/10.1007/bf00020275

[24] Lee, M. K., Barr, B. I. G. "An overview of the fatigue behavior of plain and fibre reinforced concrete", Cement and Concrete Composites, 26(4), pp. 299-305, 2004. https://doi.org/10.1016/s0958-9465(02)00139-7
[25] Seitl, S., Šimonová, H., Keršner, Z., Canteli, A. F. "Evaluation of concrete fatigue measurement using standard and non-linear regression model", Applied Mechanics and Materials, 121-126, pp. $2726-2729,2012$. https://doi.org/10.4028/www.scientific.net/AMM.121-126.2726

[26] Šimonová, H., Kucharczyková, B., Havlíková, I., Seitl, S., Keršner, Z. "Complex Evaluation of Fatigue Tests Results of Plain C30/37 and C45/55 Class Concrete Specimen", Key Engineering Materials, 592-593, pp. 801-804, 2014. https://doi.org/10.4028/www.scientific.net/kem.592-593.801

[27] Seitl, S., Miarka, P., Klusák, J., Domski, J., Katzer, J., Šimonová, H., Keršner, Z. "Change of a Crack Propagation Rate in Finegrained Cement-based Composites due to Partial Replacement of Aggregate by Ceramic Waste", Key Engineering Materials, 761, pp. 111-115, 2018.

https://doi.org/10.4028/www.scientific.net/KEM.761.111

[28] Seitl, S., Viszlay, V., Domski, J., Katzer, J. "Fracture Mechanical Properties of Cement Based Composites with Various Amount of Waste Aggregates", Procedia Engineering, 190, pp. 345-351, 2017. https://doi.org/10.1016/j.proeng.2017.05.347

[29] Mehta, P. K., Monteiro, P. J. M. "Concrete: Microstructure, Properties, and Materials", 3rd ed., McGraw-Hill Education, New York City, New York, United States, 2006.

[30] Frantík, P., Java GA package, GNU GPL licence, 2018. Available at http://www.kitnarf.cz/java [Accessed: 05.12.2018] 